\title{
Estudo de gelo de spin artificial em materiais que apresentam frustração magnética
}

\author{
Gabriel H. M. de Aguiar*, Breno M. Cecchi, Murilo F. Velo, Kleber R. Pirota
}

\begin{abstract}
Resumo
O intuito do trabalho foi estudar sistemas artificiais de spin, especificamente gelo de spin artificial, que apresentam frustração magnética. A frustração no sistema dá origem a fenômenos emergentes, como regra de minimização de energia (regra do gelo). Utilizando o processo de litografia por feixe de elétrons fabricamos as amostras em várias etapas de desenvolvimento. Por fim, considerando o efeito de proximidade, foi obtido uma amostra com sucesso. A partir de imagens de microscopia de força magnética, observamos o fenômeno de frustração nas amostras.
\end{abstract}

\section{Palavras-chave:}

nanomagnetismo, sistemas frustrados, gelo de spin artificial

\section{Introdução}

Sistemas artificiais de spin são arranjos nanométricos de ilhas magnéticas que se comportam como macrospins. A geometria favorece o fenômeno de frustração magnética, que é uma degenerescência dos estados de energia. Neste trabalho foi escolhido a geometria de kagomé, pois as interações magnéticas entre os vizinhos são equivalentes [1].

Estes sistemas são governados pela regra de gelo, a qual mantêm o sistema em estado de minimização de energia [2]. Na estrutura kagomé o estado mínimo corresponde a dois spins entrando no vértice e um saindo, ou vice-versa.

\section{Resultados e Discussão}

As amostras foram feita por processo de lift-off. O processo consiste em desenhar o padrão da estrutura em um substrato com resist por litografia e realizar a deposição do metal, e após a limpeza do resist o resultado é a estrutura metálica sobre o substrato. Devido as dimensões das ilhas foi necessário utilizar litografia por feixe de elétrons.

Para fabricar as amostrar precisou considerar o efeito de proximidade. $O$ efeito ocorre quando elétrons do feixe da litografia são refletidos no substrato $e$ colidem novamente com o resist, o sensibilizando fora do padrão desenhado. Além disso, foi feito um reescalonamento horizontal da dose (quantidade de carga por área) do feixe. O resultado é mostrado na figura 1.

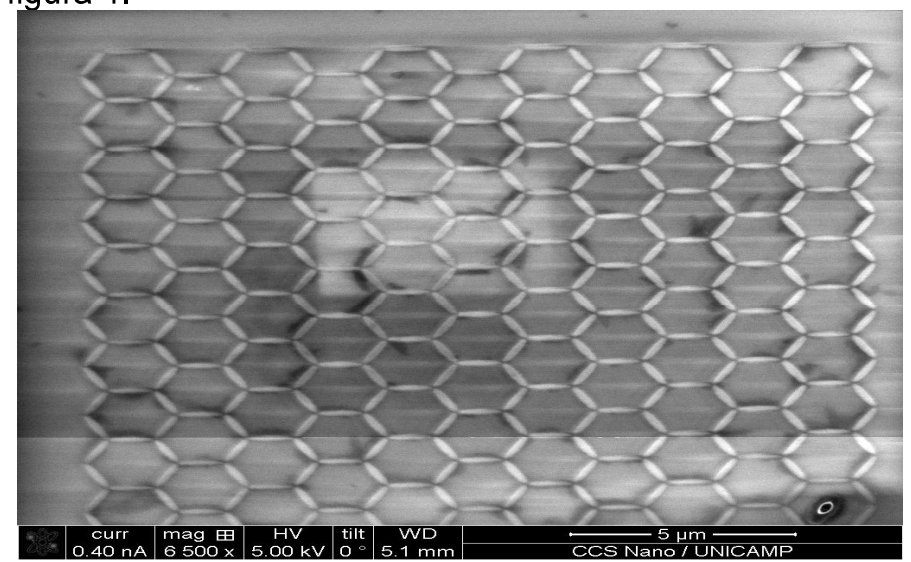

Figura 1: Amostra de estrutura kagomé 10x11 células. Imagem retirada no FIB.
Para verificar a validade da regra do gelo analisamos a amostra em um microscópio de força magnética (MFM). O microscópio mede a variação de campo magnético através de uma ponta que varre a amostra. Em geral, pontos escuros indicam um máximo do gradiente do campo, e pontos claros indicam um mínimo. A amostra foi saturada e a imagem da mensuração está na figura 2.

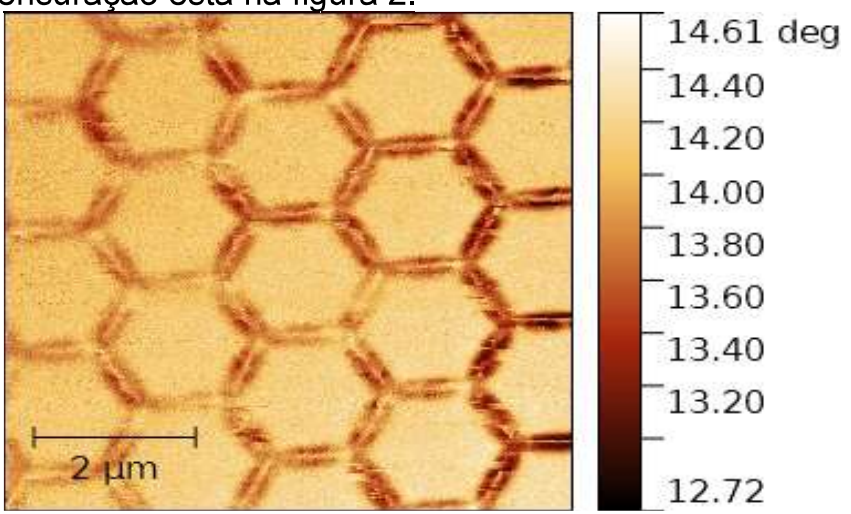

Figura 2: Medida de MFM na amostra $10 \times 11$. A escala da intensidade do gradiente está a direita.

É possível notar um padrão em todo vértice de dois pontos escuros e um claro, ou dois claros e um escuro. O padrão é interpretado como a regra de gelo, supondo um estado de minimização de energia da amostra. Porém é necessário medidas mais precisas para validar a regra e explicar as laterais escuras presentes em cada ilha.

\section{Conclusão}

No trabalho estudamos sistemas artificiais de spin que apresentam frustração magnética. Através de microfabricação foi feito uma amostra de estrutura kagomé $10 \times 11$, que foi possível a fabricação apenas quando considera o efeito de proximidade. Por análise de microscopia de força magnética interpretamos a regra de gelo no sistema em estado de saturação.

\section{Agradecimentos}

Gostaria de agradecer ao CCSnano/Unicamp, CNPq e Fapesp pelo investimento.

1.L. J. Heyderman and R. L. Stamps, "Artificial ferroic systems: Novel functionality from structure, interactions and dynamics," J. Phys. Condens. Matter, vol. 25, no. 36, pp. 1-29, 2013.

2.Qi, Y., Brintlinger, T. \& Cumings, J. "Direct observation of the ice rule in an artificial kagome spin ice." Phys. Rev. B 77, 2008 